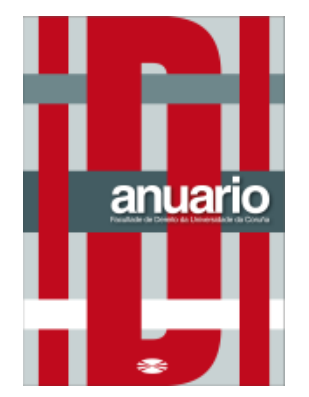

Anuario da Facultade de Dereito da Universidade da Coruña

Vol. 20 (2016), pp. 253-262

ISSNe: 2530-6324 || ISSN: 1138-039X

DOI: https://doi.org/10.17979/afdudc.2016.20.0.1924

\title{
POSIBILIDAD DE VARIACIÓN DE ADMINICULA IURIS EN EL DERECHO COMÚN Y EN LOS DERECHOS PROPIOS EN EUROPA Y EN LAS INDIAS. UNA DEMOSTRACIÓN EN TEMA DE TESTAMENTO
}

\author{
EMMA MONTANOS FERRÍN \\ Catedrática de Historia del Derecho y de las Instituciones \\ Universidad de A Coruña
}

Fecha de recepción: 8.9.2016

Fecha de aceptación: 20.9.2016

Resumen: Para salvaguardar, de manera cautelar, las disposiciones mortis causa, las normas exigen una determinada solemnidad. El testamento como categoría jurídica no cambia, pero si pueden ser objeto de variaciones normativas aspectos formales del mismo, partes secundarias, los adminicula iuris.

Palabras clave: figura jurídica; adminicula iuris; testigos; literatura jurídica europea; literatura jurídica indiana

Abstract: To safeguard mortis causa dispositions in a precautonary fashion, codes of conduct compel certain formalities. Legal status of testament does not change, but may different secondary parts of it, be subjected to formal variations, are the adminicula juris"

Keywords: testament; iuridica figure; adminicula iuris; witness; european legal literatura; "Indiana" legal literatura 
SUMARIO: I. PLANTEAMIENTO. II PRESENCIA CONTINUA DE TESTIGOS EN LA ELABORACIÓN DEL TESTAMENTO NUNCUPATIVO. III EXTRANEI ACTUS VITIANT TESTAMENTUM. IV ILLUD QUOD EST INDIVIDUUM, NON POTEST FIERI PER PARTES. V CONCLUSIÓN

\section{PLANTEAMIENTO}

Dentro de la solemnidad que las normas exigen para salvaguardar de manera cautelar las disposiciones mortis causa ${ }^{1}$, la forma del testamento es susceptible de partes secundarias, aquéllas llamadas por los juristas adminicula iuris. Precisamente partiendo de que la categoría (testamento) no cambia y sí, sin embargo, pueden ser objeto de variaciones normativas aspectos formales de la misma, planteo ahora un aspecto concreto de las solemnidades que el testamento debe revestir y que afecta a la necesidad, o no, de presencia continua de testigos en la elaboración del testamento nuncupativo en las Indias. Sigo en este planteamiento el pensamiento de Juan de Matienzo $^{2}$ y que, ya adelanto, presenta variaciones con relación al derecho común ${ }^{3}$ considerando que el testamento en cuanto a su forma a iure civili inventum y que ésta puede cambiar sus adminicula tanto por ley civil como por ius regium ${ }^{4}$.

\footnotetext{
*Investigación financiada por el Ministerio de Economía y Competitividad de España con cargo al proyecto DER 2012-31265 (“Juristas de formación europea entre España y las Indias, siglos XVI-XVIII") del que la autora, Emma Montanos Ferrín, es investigadora principal.

1 "La raffinata disciplina di ius commune sui testamento era tutta costruita sulla necessità di evitare frodi $\mathrm{e}$ violenze a damno del testatore", BELLOMO M., "Perché lo storico del diritto europeo deve occuparsi dei giuristi indiani?", Rivista Internazionale di Diritto Comune, 11, 2000, pág. 28. En efecto, "è noto che il testamento è un atto grave, soggetto a mille possibili frodi, e per questo circondato dalle cautele del legislatore", CONDORELLI O., "Norma giuridica e norma morale, giustizia e salus animarum secondo Diego de Covarrubias. Riflessioni a margine della Relectio super regula Peccatum", Rivista Internazionale di Diritto Comune, 19, 2008, pág. 25. Condorelli aborda en esta investigación el ámbito de la historia del pensamiento teológico y jurídico en el tema que afronta Diego de Covarrubias en su Relectio super regula "Peccatum" planteando "l'interconnessione tra morale, teologia e diritto", O, "Norma giuridica e norma morale", pág. 33. En otro estudio el mismo autor, fijándose en la cautela que supone el juramento, manifiesta cómo "l'esperienza giuridica del diritto comune attesta l'uso del giuramento al fine di rendere irrevocabile il testamento", CONDORELLI, O., "Il testamento confermato dal giuramento tra diritto canonico e diritto civile (secoli XIII-XVIII)", Der Einfluss der Kanonistik auf die europäische Rechtskultur. I. Zivil- und Zivilprozessrecht", herausgegeben von Orazio Condorelli Franck Roumy - Mathias Schmoeckel, Norm und Struktur 37.1, 2009, pág. 335. En un tercer artículo Condorelli analiza los canonistas que encuadran la normativa constituida por las leyes romanas sobre las formalidades testamentarias y las normas canonísticas que incidían sobre este campo específico, CONDORELLI, O., "Ricerche intorno a una decretale di Innocenzo III indirizzata all'arcivescovo di Lund (Ex litteris, X.1.4.2, 1198)”, Rivista Internazionale di Diritto Comune, 21, 2010, págs. 55-92.

${ }^{2}$ MATIENZO, J. Commentaira [sic]... in librum quintum recollectionis legum Hispaniae, tit. IV, de los testamentos, y commissarios para los poder hazer, y de los executores testamentarios. 1. I. que pone la solemnidad de testigos que son necesarios nel testamento nuncupativo, Mantuae Carpentanae, 1580, fols. 62va-101vb. Del amplio contenido, que abarca 19 glosas a esta ley, he puesto como objeto de mi estudio las siete primeras (fols. $62 \mathrm{va}-72 \mathrm{vb}$ ) que, a mi modo de ver, resultan suficientemente expresivas al objeto de mi investigación.

3 "Ancora una volta risulta chiaro ed evidente il legame funzionale che esisteva fra il ius commune, portatore di principi e di problemi di base, e il ius proprium, costretto ad essere variegato nei suoi contenuti per essere funzionale ai tempi, ai luoghi, alle circostanze", BELLOMO, M., "Perché lo storico del diritto europeo debe occuparsi dei giuristi indiani?" pág. 30.

${ }^{4}$ MATIENZO, J., "Commentaira. 1. I. glossa IV sobre testes testamenti nuncupativi”, fol. 68va nr. 14
} 


\section{PRESENCIA CONTINUA DE TESTIGOS EN LA ELABORACIÓN DEL TESTAMENTO NUNCUPATIVO}

Juan de Matienzo da comienzo a la glossa $\mathrm{IV}^{5}$ de la siguiente forma: "Testes testamenti nuncupativi debent esse praesentes confectioni testamenti iure regio, et communi imperatorum" marcando así el contenido paralelo o similar en este punto entre la legislación real y el derecho común: "ídem statutum erat iure communi imperatorum" ". El aspecto concreto al que se refiere el indianista es al de la necesidad de que esté presente un cierto número de testigos en la confección del testamento nuncupativo que será el de tres al menos, según el derecho real castellano, en el realizado coram tabellione. El indianista utiliza como instrumentos operativos, y por lo que se refiere al ius commune, las disposiciones: 1. cum antiquitas (C.6.23.28), 1. casus (C.6.23.8) y l. furiosum (C.6.22.9) que fundamentan su afirmación sobre la exigencia de presencia de testigos. En concreto, la 1. cum antiquitas refiere la necesidad de observancia de ciertas formalidades para la confección del testamento y en su $\S$ quum autem recuerda la necesidad de asistencia de siete testigos, aunque en algún caso muy específico abre claramente la posibilidad de reducción del número a la firma del mismo por cinco testigos para su validez ${ }^{8}$.

\section{EXTRANEI ACTUS VITIANT TESTAMENTUM}

Matienzo plantea también la cuestión sobre si los testigos exigibles de forma presencial en la elaboración del testamento han de ser siempre los mismos y utiliza con gran fluidez parte importante de la literatura jurídica que conoce de forma admirable. En este punto trae a colación en primer lugar a Baldo quien, al comentar la 1. cum antiquitas y cuestionarse si una parte del testamento puede ser probada por siete testigos y otra parte por otros siete, mantiene que han de ser siempre los mismos sin que quepan excepciones como podría ser la subrogación de testigos ex causa necessitatis, o aunque los testigos que hicieran la subrogación pudiesen probar "totum tenorem testamenti perfectum" porque no pueden ser considerados legítimos ya que "totum nesciunt". En este mismo sentido y siguiendo a Baldo, pero de forma incluso más expresiva, determina Paolo di Castro, al comentar esta misma disposición, que aunque los nuevos testigos pudieran testificar sobre el contenido de todo el testamento, no podrían repetir testificando los gestos que tuvieron lugar al elaborarlo ${ }^{10}$. Muy didáctico resulta, a mi modo de ver, Cino da Pistoia quien estructura la misma interpretación partiendo de la situación de un largo período en el que unos testigos son subrogados por otros y plantea

\footnotetext{
${ }^{5}$ MATIENZO, J., "Commentaira .1. I. glossa IV, testes testamenti nuncupativi debent esse presentes", nrs. $1-21$, fols. 66vb-69va

${ }^{6}$ MATIENZO, J., “Commentaira .1. I. glossa IV, testes testamenti debent esse presentes”, fol. 66vb, nr. 1

${ }^{7}$ MATIENZO, J., "Commentaira .1. I. glossa IV sobre testes testamenti nuncupativi”, fol. 66vb. nr. 1

${ }^{8}$ C.6.23.28.1: "Si quid autem necessarium advenerit et in ipsum corpus laborantis respiciens contigerit, id est vel victus necessarii vel potionis oblatio, vel sanitas testatoris pericliator, vel si quis necessarius naturae usus ad depositionem superflui poderis immineat vel testatori vel testibus, non esse ex hac causa testamentum subvertendum, licet morbus comitialis, quod et factum esse comperimus, uni ex testibus contigerit, sed eo quod urguet et imminet repleto vel deposito iterum solita per testamenti factionem adimpleri".

${ }^{9}$ BALDO, Comm. in de testamentis, 1. cum antiquitas, Venetiis, 1586, fol. 67va

10 “.... si propter necessitatem aliquis ex testibus se absenter... et sic loco eius alius surrogatur... alii loco illorum surrogarentur in gesta non repeterentur...", PAOLO DI CASTRO, Comm. in de testamentis, l. cum antiquitas, Ludguni, 1561, fol. 293vb
} 
la pregunta de qué actos son considerados voluntad del testador y qué actos los testigos "coram his processissent"". Manifiesta, uniéndose al pensamiento de los moderniores, que han de tenerse en cuenta los testigos que permanecieron siempre y coliga al respecto dos estimaciones notables. La primera mantiene que, sobre lo que se dice hecho in continenti, cualquier acto extrínseco y voluntario que intervenga es nulo, y concluye fundamentándose en la 1. perfecta (C.8.56 [55].4) - que determina la no admisión de condiciones posteriores en la donación perfecta - que de la misma manera que "antequam contractus sit absolutus a partibus... antequam a partibus testamentum fuerit absolutum"12. La segunda estimación lleva a Cino a la declaración de que "extranei actus vitiant testamentum"13. De forma más radical y escueta determina Iason del Mayno que cuando es necesario remover algunos testigos del testamento, antes de que éste esté completado, deben de ser repetidos de nuevo todos los actos de formalización testifical ${ }^{14}$.

La exigencia de las formalidades concretas exigibles está bien presente también en el contenido de la 1. casus que es el segundo gran pilar en que se apoya Juan de Matienzo. Esta disposición mantiene que, por caso de fuerza mayor y de nueva contingencia derivada del temor de contagio a causa de una enfermedad que aqueja al testador, se puede dispensar la reunión de testigos en ese momento; sin embargo, no se suprime la formalidad de reunir el número de éstos. De nuevo el jurista indiano adopta los comentarios que sobre esta ley aportan distintos juristas. Por ejemplo, Baldo mantiene que, por razón de necesidad, se puede suspender de forma temporal una disposición "sed non in totum tollitur" y que incluso una sentencia podría por ello hacerse de noche siempre que se observasen las restantes solemnidades, lo que le lleva incluso a afirmar - en aras del mantenimiento de la solemnidad que debe de observarse - que también el leproso es testigo idóneo ${ }^{15}$. Con mucho más detalle insiste en términos similares Paolo di Castro cuyo pensamiento al respecto es claro en el sentido de que los testigos del testamento deben de ser siete y deben de estar presentes en la totalidad de los actos en los que el testador expresó su voluntad: "debeant ese septem, qui audierunt a principio, medio et fine" e insiste en que, incluso en el caso en que uno de ellos deba de ser sustituido por razón de necesidad, deben de repetirse todos los actos del proceso en que el nuevo testigo no estuvo presente ${ }^{16}$.

\footnotetext{
${ }^{11} \mathrm{CINO}$, Comm. in de testamentis, 1. cum antiquitas, Francoforti, 1578, fol. 369vb

${ }^{12}$ CINO, op. et loc. cit.

${ }^{13}$ CINO, op. et loc. cit.

14 “... quando aliquis testes testamentarii ex necessitate removentur antequam totum testamentum compleatur, deinde eorum loco alii testes surrogantur propter omnia prius acta dentur de nuovo repetit et prius recitari", Iason del Mayno, Comm. in de testamentis, 1. cum antiquitas, nr.8 (Ludguni 1581) fol. $94 \mathrm{va}$

15 "Ratione casus emergentes, aliquid interdum differtur, quod alias non differretur, et licet differatur solemnitas, tamen non in totum abrumpitur, hoc dicit... quod propter necessitatem iuris dispositio ad tempus suspenditur, sed non in totum tollitur... quod propter necessitatem, posset sententia feri de nocte, servatis tamen caeteris solemnitatibus. Si enim non servaretur solemnitas, non faceret sententiam valere necessitas... ítem not. quod licet testis sit leprosus, tamen est idoneus testis, possunt tamen alii testes nolle secum interesse...", BALDO, Comm. in de testamentis, 1. casus, fol. 61vb

16 "Propter necessitatem dispositionis iuris interdum suspenditur, non autem in totum tollitur... testes coram testatore forent congregati, et testator incepisset suam voluntatem exprimere uni ex testibus supervenit morbus caducus, propter quod alii testes deterriti fecerunt inde ipsum moveri et interim testator supersedit in procedendo ulterius, et expectando per magnum spacium propte resipisceret et rediret et interim de aliis impertinentibus fuit locutus eum testibus, postea ille redimit et tutator continuavit. Quaeritur an testamento reddatur nullum propter illum intervallum videbatur... quia uno contextu debet testium inchoari, perfici sine interpositione spacii... quia istud intervallum ex quadam necessitate
} 


\section{ILLUD QUOD EST INDIVIDUUM, NON POTEST FIERI PER PARTES}

La 1. furiosum es el tercer pilar en que Juan de Matienzo fundamenta la exigencia presencial de testigos en el testamento. Esta disposición mantiene la posibilidad de que el demente, en momentos de lucidez, pueda expresar su voluntad de hacer testamento, y si con sano juicio lo hubiera comenzado a hacer y lo hubiera concluido sin que lo interrumpiera la enfermedad, subsiste el testamento siempre que hubiera concurrido todo lo demás a que se presta legítima observancia en actos de esta naturaleza. El testamento es un acto único - aunque, por ejemplo, Bartolo admite que por intervalo pequeño y por necesidad de la naturaleza el testamento no se vicia ${ }^{17} \mathrm{y}$ lo mismo que estamos haciendo notar sobre la asistencia de testigos a todo su desarrollo, del mismo modo tampoco aquél no se puede expresar a intervalos lúcidos del demente sino en un solo período de lucidez total, estado que es difícil probar, como a sensu contrario mantiene Baldo al indicar que la locura es de difícil prueba ${ }^{18}$. A mayor abundamiento resalto la clarísima expresión que utiliza Cino: "illud quod est individuum, non potest fieri per partes" ${ }^{\prime 19}$, y de forma similar Iason del Mayno ${ }^{20}$, traídos a colación por Matienzo para insistir en la demostración de los actos de última voluntad en que deben de estar presentes todos los testigos. Concluye este punto el jurista indiano afirmando que, teniendo en cuenta la literatura jurídica - de la que he mostrado algunos exponentes -, queda claro que iure communi no se acepta el testamento dividido, una parte con la intervención de siete testigos, otra parte con la intervención de otros siete, como tampoco iure regio con cinco testigos o con tres ("si fiat coram tabellione"), no pudiendo intervenir en una parte cinco y en otra otros cinco ${ }^{21}$. El indianista se apoya ad abundantiam también en Bartolo, Iason del Mayno considera que la situación si los testigos del testamento así efectuado no puede probar perfectamente todo el tenor del testamento $^{22}$, Alexander Tartagni quien ni siquiera admite la perfección del testamento realizado con un número no suficiente de testigos en tiempos de peste, ni el elaborado por causas pías, porque ése no está legítimamente probado de esta forma, así como tampoco lo está el que es realizado por causa de necesidad con subrogación de testigos (una parte por siete y otra parte por otros siete) y aunque los testigos "probent totum tenorem testamenti, nihil probent" ${ }^{, 23}$.

interpositum est, unde non vitiat, sed potuit suspendi. Sed quid si testator coram illis sex continuabit perfecit, certe non valet, quia tunc solemnitatem omittit, cum debeant ese septem, qui audierunt a principio, medio et fine... Item loco illius testes potius subrogari alius coram eo repeti id, quod prius dixerat, ut ille sciat omnia...", PAOLO DI CASTRO, Comm. in de testamentis, 1. casus, fol. 40va

17 "Modicum intervallum seu actus serius ex necessitate nature intervenientis testatori vel testibus testamentum non vitiat", BARTOLO, Comm. in de testamentis, 1. cum antiquitas, (Venetiis, 1506; reprod. anast., vol. IX, Il Cigno Edizioni, Roma 1998) fol. 19va

18 "Furorem probari est difficilis probationis, nec creditur testi sine ratione rationis causa", BALDO, Comm. in de testamentis, 1. furiosum, fol. $59 \mathrm{va}$

${ }^{19}$ CINO, "Comm. in de testamentis, 1. furiosum", fol. $365 \mathrm{vb}$

20 “... testamentum est actus individuus: ideo non potest valere imperfectum facit...”, IASON DEL MAYNO, Comm. in de testamentis, 1. furiosum, nr.11, fol. 78va

21 “... Ex quo omnes asseverant iure communi non posse probari testamentum divisim: altera eius pars per septem testes, altera per alios septem, prout nec iure regio per qinque vel tres, si fiat coram tabellione, si qinque dicant se scire partem eorum, quae in testamento continentur, et alii quinque aliam partem...", MATIENZO, J., Commentaira .1. I. glossa IV sobre testes testamenti nuncupativi, fol. 66vb, nr. 1

22 “... una pars testium non potet probari per septem testes, dicentes se illud scire et non plus, alia pars per alios septem, quia testes testamentarii nihil probant nisi probent totum tenorem testamenti perfecte...", IASON DEL MAYNO, "Comm. in de testamentis, 1. cum antiquitas", nr. 9, fol. 94va

23 "Praeterea conmuniter tenetur non ese verum, quod sufficiat testamentum ese factum coram imperfecto numero testium tempore pestium... Secundo principali fundamento moveor ad ostendum propter dicto 
Sin embargo, Vázquez de Menchaca, que tiene presente lo que parece entender como diversidad de interpretaciones en la literatura jurídica, mantiene lo contrario iure regio. Este jurista plantea, por un lado, un paralelismo con los actos inter vivos para los que iure civile se admite que puedan ser probados membratim, una parte por unos testigos y otra parte por otros ${ }^{24}$ y llega a afirmar: "in actibus autem inter vivos non sic erit [se refiere a la nulidad del testamento por inobservancia en cuanto al número de testigos presenciales], etiam in terminis iuris communis" 25 . Por otro lado, encuentra apoyo en la 1. Gallus § ille casus (D.28.2.29§15) que refiere una situación sucesoria en la que podrían caber dos interpretaciones - lo mismo que en el caso que nos ocupa respecto de la necesaria comparecencia o no de todos los testigos exigibles para la validez del testamento - pero que se resuelve afirmando que se tiende a que la ley impida la invalidez de los testamentos ${ }^{26}$, afirmando Vázquez de Menchaca: "ubi in simili per omnes... licet ex quadam"27.

Sale al paso Juan de Matienzo de esta interpretación que mantiene una posición contraria iure regio que no considera ajustada y afirma que no es suficiente para la validez del testamento nuncupativo que todos los testigos estén presentes a no ser que todos entiendan, perciban bien y puedan definir hasta la mínima partícula del testamento $^{28}$, fundamentando su pensamiento esencialmente en Baldo y en Paolo di Castro en sus comentarios a la 1 . cum antiquitas en los que mantienen, como hemos visto, que los testigos exigibles han de ser siempre los mismos y conocer por entero el testamento $^{29}$.

El jurista indiano matiza todavía más su postura al asumir comentarios de gran parte de la literatura jurídica que sostiene que para la validez del testamento nuncupativo es necesario que los testigos no solo estén presentes y entiendan las diferentes actuaciones, sino que además insisten de forma muy expresiva en que han de conocer el rostro del testador ${ }^{30}$. En este punto concreto trae a colación diversos

testamento non est legitimè probatum... Et quod ibi ad propositum... singulariter dixit Baldo ibi quaerendo an una pars testamenti probari possit per septem testes dicentes se illud scire, et non plus, alia pars possit probari per alios septem testes... Sed dicit, in contrarium est casus in dicta lege cum antiquitas, quia nisi probetur subrogatio testium ex causa necessitatis non probat... nisi testes probent totum tenorem testamenti, nil probent...", ALEXANDER TARTAGNI, Consiliorum seu responsorum, Venetiis, 1597, lib. 2, consilium 177 nr. 8, fol. 145va

24 VÁZQUEZ DE MENCHACA, De successionum creatione, progresu et resolutione Tractatus (Salamanca, 1559), 1“. pars, 1. 3, § 22, nr. 91, fol. 85vb: “... Quinimo in actibus inter vivos etiam de iure civili admittitur, ut membratim fiat probatio, ut sic una pars contractus possit probari per duos testes, alia verò pars per alios duos testes...".

${ }^{25}$ VÁZQUEZ DE MENCHACA, “Tractatus", $1^{\mathrm{a}}$. pars, 1. 3, § 30, nr. 11, fol. 85vb

${ }^{26}$ D.28.2.29§15: "Ille casus in difficili est, si filium habeas et nepotem nondum natum instituas isque nascatur vivo patre suo ac mox pater decedat: non enim suus heres est tempore quo nascatur nec posteriori alii succedendo prohiberi videtur rumpere quam qui iam natus erit. Denique et superiore capite ut liceat institui nondum natos, qui cum nascentur sui erunt, permitti, posteriore capite non permittit institui, sed velat rumpi neve on eam rem minus ratum esset, quod succedit, porro procedere debet, ut utiliter sit institutus: quod nullo iure potuit qui nondum natus erat. Iuliano tamen videretur duobus quasi capitibus legis commixtis in hoc quoque inducere legem, ne rumpantur testamenta".

${ }^{27}$ VÁZQUEZ DE MENCHACA, op. et loc. cit.

28 “....Nec satis este os ese praesentes, nisi omnes intelligant et percipiant, quae in testamento nuncupativo scripta sunt, ita ut nullam particulam, etiam, minimam percipere definant. Non enim sufficit testes omnes testamento ese praesentes, nisi praeterea omnia quae ibi acta fuerint plene intellexerint...", MATIENZO, J, “Commentaira”. 1. I. glossa IV sobre testes testamenti nuncupativi, fol. 67va, 2

${ }^{29}$ Vid. supra notas 9 y 10

30 “... Quinimo non sufficit testes ese praesentes et inteligentes, nisi in conspectu testatoris fuerint, eumque viderint et agnoverint et licet antea non agnoverint, ut ex visu eum agnoscant hec aliter quicquam 
comentarios a dos disposiciones: por una parte, a la 1. si non speciali (C.6.23.9) que determina la absoluta necesidad - para que el testamento sea válido - de que los testigos desempeñen su oficio en presencia del testador, a no ser que exista sobre ello un privilegio patriae que dispense la observancia de las formalidades del derecho ${ }^{31} \mathrm{y}$, por otra parte, a la 1. si unus (C.6.23.12) que establece que si hubiera faltado uno de los siete testigos o todos los testigos no lo hubieran sellado en presencia del testador se invalida en derecho el testamento ${ }^{32}$. Bartolo y Baldo de forma muy clara dispone que cuando se hace testamento los testigos tienen que estar "in conspectu testatoris" y tienen que estar viendo al testador sin obstáculo, a no ser que exista en la patria un privilegio que exima esta observancia ${ }^{33}$, utilizando una expresión similar $\mathrm{Cino}^{34}$, Iason del Mayno quienes además insisten en la firma o sellado que han de hacer los testigos en presencia del testador $^{35}$.

El doctor burgensis (Marcos Salón de Paz) plantea, sin embargo, la duda sobre si es necesario que los testigos de los testamentos deban conocer al testador ${ }^{36}$. Propone las dos interpretaciones pro y contra y al tratar de demostrar la que claramente es la que él mantiene sobre la no necesidad comienza afirmando que "non esse opus testes testamentorum cognoscere testatorem" 37 como ocurre, por ejemplo, en el testamento que hacen los peregrinos ${ }^{38}$. Apela como fundamentación a la legislación regia que en Partidas 6, 1,30 dispone "libre poder" a los peregrinos para hacer testamento como éstos ordenasen $^{39}$. En la distancia de siglos, Gregorio López en su glosa a esta disposición y a propósito de la mencionada expresión mantiene, siguiendo a otros juristas, que con

valet testamentum...", MATIENZO, J., "Commentaira" .1. I. glossa IV sobre testes testamenti nuncupativi, fol. 67va, nr. 3

${ }^{31}$ C.6.23.9: "si non speciali privilegio patriae tuae iuris observatio relaxata est et testes non in conspectu testatoris testimoniorum officio functi sunt, nullo iure testamentum valet".

${ }^{32}$ C.6.23.12: "Si unus de septem testibus defuerit vel coram testatore omnes verint, iure deficiat testamentum. 1 De his autem, quae interleta sive supra scripta dicis, non ad iuris sollemnitatem, sed ad fidei pertinet quaestionem, ut appareat, utrum testatoris voluntate emendationem meruerunt, vel ad altere inconsulte deleta sunt, an ab aliquo falso haec fuerint commissa".

33 "Quando fit testamentum testes debent ese in conspectu testatoris, nisi ex privilegio aliud sit concessum... ergo quod testes debent esse in cum testatoris, sin non sufficeret si esset cortina in medio...", Bartolo, Comm. in de testamentis, 1. si non speciali, fol. 17vb; “... Defectum solemnitatis facit testamentum deficetur...", BARTOLO, Comm. in de testamentis, 1. si unus, fol. 17vb. "Quando fit testamentum, testes debent ese in conspectu testatoris, et officio suo sfungi in subscriptionibus et aliis solemnitatibus, nisi per privilegium iuris observantia patriae sit remissa...", BALDO, Comm. in de testamentis, 1 . si non speciali, fol. $61 \mathrm{vb}$

${ }^{34}$ CINO, Comm. in de testamentis, 1. si non speciali, fol. 366vb

35 “... quod olim non erant sigilla, sed annulli: unde omnes testes in praesentia testatoris uno annulo, suo vel alieno signaverunt, valet... Hodie convenerunt homines omnes habere sigilla et cum illis signant...", CINO, "Comm. in de testamentis, 1. si unus", fol. 366vb. "... testes debent essere in conspectu testatoris quando fit testamentum, nisi speciali privilegio aliud sit concessum... Vel melius testes testamentarii debent fungi eorum officio in suscribendo et sigilando in praesentia testatoris nisi ex privilegio aliud sit inductum...", IASON DEL MAYNO, Comm. in de testamentis, 1. si non speciali, in prin., fol. 83vb 36 "...obiter hic occurrit dubium si an testes testamentorum debeant cognoscere testatorem...", SALON DE PACE, “Ad leges Taurinas insignes commentarii”, 1ª pars. 1. 3, tertia conclusio, nr. 347, fol. $215 \mathrm{va}$ ${ }^{37}$ Op.et loc. cit.

38 “... peregrinos et testibus ignotos testamentum confiscere posse, et in eorum testamentis testes ipsum testatorem non agnoscentes inscribi posse...", MARCOS SALÓN DE PAZ, “Ad leges Taurinas insignes commentarii", $1^{\mathrm{a}}$. pars. 1.3 , tertia conclusio, nr. 348 , fol. $215 \mathrm{va}$-vb

${ }^{39}$ Partidas 6,1,30: “... tenemos por bien, e mandamos, que ayan libre poder para fazerlo; et como quier que ellos ordenaren, e establescieren, o mandaren fazer de sus cosas con razón, et con derecho, assi lo otorgamos, et tenemos por bien que vala...”. 
ésta se quita toda solemnidad de derecho civil a esta formalidad testamentaria ${ }^{40}$. Marcos Salon de Paz es consciente de que esta ley "confecta fuisse peregrinorum favore et ita in contrarium videtur esse ius commune" 41 ; a pesar de ello mantiene una interpretación extensiva y sostiene, haciéndose eco de una importante literatura jurídica, que cuando en un instrumento jurídico es necesario para su formalización la presencia de testigos, no se puede exigir que los contrahentes o disponentes los conozcan ${ }^{42}$ siguiendo en este punto a Boerio quien afirma en extenso que no es necesario que las partes de un negocio jurídico conozcan a los testigos ${ }^{43}$. Todavía, si cabe, resulta más clara en el escenario que expone Juan de Matienzo la afirmación de Vázquez de Menchaca quien, siguiendo una seleccionada communis opinio, manifiesta que, si bien deben de ser seis los testigos testamentarios in conspectu testatoris, vale el testamento aunque esta situación no fuera posible de alcanzar ${ }^{44}$. Nuestro indianista continúa exponiendo esta posición iure regio que todavía afirma más claramente Vázquez de Menchaca al aseverar que según el derecho regio vale el testamento aunque no estén presentes in conspectu testatoris los testigos si testamentarii testes sufficienter intellexerint en su realización, a la vez que pone de relieve el paralelismo que observa con la ejecución de los actos inter vivos en que no son necesarios testigos in conspectu de los contrayentes, y siendo consciente que de iure communi no es as ${ }^{45}$ concluyendo: "quia non minus utile, quam novum"

Se sigue observando de forma muy interesante el juego del sistema de ius commune al plantearse el tema de la necesaria presencia, o no, de todos los testigos en la realización de todo el testamento. Vázquez de Menchaca destaca que en la realización de actos inter vivos el ius civile admite que una parte de un contrato sea probada por unos testigos y otra parte por otros, lo mismo que el derecho regio ${ }^{47}$. Sin embargo, en los actos de última voluntad, existe diferencia de soluciones jurídicas: el derecho civil exige la necesaria presencia de todos los testigos en todas la partes de su elaboración ${ }^{48}$,

\footnotetext{
${ }^{40}$ GREGORIO LÓPEZ, Glossa a Partidas 6,1,30, verbo libre poder: “... quod per hoc verbum videtur tolli omnis solemnitas juris civilis circa testamenta peregrinorum...".

${ }^{41}$ MARCOS SALÓN DE PAZ, "Ad leges Taurinas insignes commentarii”, $1^{\circ}$.pars. 1.3, tertia conclusio, nr. 348 , fol. $215 \mathrm{vb}$

42 “... quia cum testes in instrumento inscribuntur de iure non quidem exigitur, contrahentes seu disponentes cognoscere...", MARCOS SALÓN DE PAZ, "Ad leges Taurinas insignes commentarii", $1^{\text {a }}$. pars. 1. 3, tertia conclusio, nr. 349, fol. $215 \mathrm{vb}$

43 “... vel quod partes cognoscant testes non requiritur...", NICOLÁS BOERIO, "Decisionum aurearum, pars prima, Venetiis, 1576, dec. 118, fol. 250va

44 “... Seis propter testes testamentarii esse debent in conspectu testatoris, neque aliter quicquam valet testamentum, ut est communis opinio...", VÁZQUEZ DE MENCHACA, "Tractatus", 1ª pars, lib. $3 \S$ 30, nr. 7, fol. 193va

45 ".. de iure civil iidem testes testamento adhibiti oporteat ut toti testamento fuerint praesentes...", VÁZQUEZ DE MENCHACA, "Tractatus", 1'. pars, lib. 3 § 30, nr. 11, fol. 193vb

46 "Licet in actibus inter vivos non sit necesse testes esse in conspectu contrahentium, si aliter percipiunt quae aguntur ab ipsis... Ergo de iure regio cum testamentorum solemnia ad probationem tantum, non etiam ad formam desiderentur, si testamentarii testes sufficienter intellexerint, quod a testaore agebatur, valebit testamentum, per praedicta, licet non sic de iure communi, quiod nota, quia non minus utile, quam novum", VÁZQUEZ DE MENCHACA, "Tractatus", 1ª pars, lib. 3 § 30, nr. 8, fol. 193va

47 "Quinimo in actibus inter vivos etiam de iure civil admittitur, ut membratim fiat probatio, ut sic una pars contractus possit probari per duos testes, alia vero pars per alios duos testes... Ergo probatio membratim facta admittitur in actibus inter vivos iure tam communi, quam regio...", VÁZQUEZ DE MENCHACA, "Tractatus", $1^{\mathrm{a}}$. pars, lib. $3 \S 30$, nr. 13, fol. 193vb

48 " ... ut licet de iure civil oporteat, quod omnes testes intelligant omnia in testamento contenta, ita ut nullam particulam etiam minimam desinant intelligere singuli testes, nec enim satis est, quod fuerint praesentes, ut proxime dicebamus, nisi praeterea omnia, quae ibi agebantur...", VÁZQUEZ DE MENCHACA, "Tractatus", $1^{\mathrm{a}}$. pars, lib. $3 \S 38$, nr. 14, fol. 193vb
} 
mientras que el derecho regio no mantiene esta exigencia pudiendo probar una parte del testamento unos testigos y otra parte otros ${ }^{49}$. Concluye afirmando que "in ultimis voluntatibus idem erit iure regio, non sic de iure communi" ${ }^{\text {"50 }}$.

Juan de Matienzo sin embargo mantiene que, ni desde el punto de vista teórico ni práctico, debe obviarse la solemnidad que con relación al testamento ha de observarse y que es la contenida en la legislación real, en la ley 3 de Toro - que impone la debida presencia de los testigos ${ }^{51}$-, a riesgo de que no sea válido el testamento que no siga los requisitos en la legislación real determinados ${ }^{52}$. Trae a colación ab imis fundamentis la 1. cum hi $\S$ si praetor (D.2.15.8.17) que determina la nulidad de la transacción en la que siendo solicitada la intervención del pretor en la realización de la misma y teniendo éste encomendado el examen del asunto, lo hubiera cedido, o descuidado. o no hubiese examinado todo lo que el discurso imperial exige, aunque hubiera investigado algo de ello $^{53}$. El indianista se apoya también en una importante selección de literatura jurídica - Bartolo, Baldo, Rosciate, Iason del Mayno.... - para insistir en el alcance y contenido del término 'deben' utilizado por la legislación real para establecer la presencia de los testigos en los diversos actos de elaboración del testamento y de los que, entre todos, destaco la afirmación de Felino cuando de forma rotunda sostiene que debere "importat neccessitatem",54.

No es de extrañar que a Juan de Matienzo le preocupe la seguridad en la realización de los actos de disposición mortis causa, pues en muchos casos harían referencia a grandes patrimonios (tierras, minas). Probablemente y para evitar posibles fraudes que podrían darse teniendo en cuenta la lejanía de las tierras de Indias con respecto a los reinos peninsulares, el traslado al Nuevo Mundo de emprendedores y de servidores de plazas que dejaban familias y comenzaban otras podía prestarse a engaños que podrían repercutir en los destinatarios del patrimonio hereditario, amén de la propia laxitud tendente en la aplicación de la normativa regia que conllevaría la propia lejanía de la Corona.

\section{CONCLUSIÓN}

Es una muestra más del ejercicio de una 'categoría' (figura) jurídica europea, el testamento, utilizado en los territorios de la monarquía española y que no coincide en el

\footnotetext{
49 “... Tamen de iure regio, testes eosdem totum testamenti tenorem probare non erit necesse: quinimo fat erit, si pars testamenti per septem testes probetur, et alia pars eiusdem testamenti probetur per alios testes diversos, licet eorum nullus sit, qui totum testamenti tenorem cognitum habuerit...", VÁZQUEZ DE MENCHACA, "Tractatus", $1^{\mathrm{a}}$. pars, lib. $3 \S 30$, nr. 12, fol. 193vb

${ }^{50}$ VÁZQUEZ DE MENCHACA, "Tractatus", $1^{\mathrm{a}}$. pars, lib. $3 \S 30$, nr. 13, fol. 193vb

${ }^{51}$ Insistiendo también la mencionada ley de Toro en que "... si no tuvieren la dicha solemnidad de testigos, mandamos que non fagan fee ni prueba en juicio ni fuera del".

52 “... Atque ita sufficeret sufficienter probari, licet formaliter non probetur, non tamen crederem admitti posse in praxi eius sententiam hoc in regno, nec in theorica sustirreri, est enim contra communem nostrarum sententiam commentantium dictum 1.3 Tauri qui omnes concedunt esse pro forma inductam eam testamentorum solemnitatem in hac lege... qua deficiente, testamenta corrunt...", MATIENZO, J., "Commentaira" .1. I. glossa IV sobre testes testamenti nuncupativi, fol. $67 \mathrm{va}$, nr. 6

${ }^{53}$ D.2.15.8.17: "Si praetor aditus citra causae cognitionem transigi permiserit, transactio nullius erit momento: praetori enim ea res quaerenda commissa est, non neglegenda nec donanda, sed et si non de omnibus inquisierit, quae oratio mandat, hoc est de causa de modo de personis transigentium, dicendum est, quamvis de quibusdam quaesierit, transactionem esse irritam".

${ }^{54}$ FELINO SANDEI, "Commentariorum... [sic] doctissimorum virorum adnotationibus atque rerum Summis...", Ludguni, 1587, cap. nam concupiscientiam, nr. 6, fol. 17vb
} 
aspecto formal de su desarrollo en los reinos hispanos - peninsulares y ultramarinos con las reglas del ius commune, pero no coincide por los admicula iuris, según una praxis doctrinal interna en el sistema del ius commune, para la cual son válidos los admicula iuris, porque consienten adecuar la forma rígida de toda categoría jurídica, en nuestro caso del testamentum, a las situaciones locales, varias e imprevisibles como pueden ser también las diversas circunstancias sociales del Nuevo Mundo.

\section{BIBLIOGRAFÍA}

BALDO DEGLI UBALDI, Super codicis commentaria VI. Comm. in de testamentis, 1. cum antiquitas (Venetiis 1586).

BARTOLO DA SASSOFERRATO, Commentaria in secundam Codicis partem IX. Comm. in de testamentis, 1. cum antiquitas, (Venetiis, 1506; reprod. anast., vol. IX, Il Cigno Edizioni, Roma 1998)

BELLOMO M., "Perché lo storico del diritto europeo deve occuparsi dei giuristi indiani?", Rivista Internazionale di Diritto Comune, 11, 2000. CINO DA PISTOIA, Lectura in Codicem. Lectura in de testamentis, 1. si non speciali (Francoforti 1578).

CONDORELLI O., "Norma giuridica e norma morale, giustizia e salus animarum secondo Diego de Covarrubias. Riflessioni a margine della Relectio super regula Peccatum”, Rivista Internazionale di Diritto Comune, 19, 2008.

CONDORELLI, O., "Il testamento confermato dal giuramento tra diritto canonico e diritto civile (secoli XIII-XVIII)", Der Einfluss der Kanonistik auf die europäische Rechtskultur. I. Zivil- und Zivilprozessrecht", herausgegeben von Orazio Condorelli Franck Roumy - Mathias Schmoeckel, Norm und Struktur 37.1; Böhlau, Köln-WeimarWien 2009.

CONDORELLI, O., "Ricerche intorno a una decretale di Innocenzo III indirizzata all'arcivescovo di Lund (Ex litteris, X.1.4.2, 1198)", Rivista Internazionale di Diritto Comune, 21, 2010, págs. 55-92.

IASON DEL MAYNO, Commentaria in secundam codicis partem. Comm. in de testamentis, 1. furiosum (Ludguni 1581).

MARCOS SALÓN DE PAZ, “Ad leges Taurinas insignes commentarii” (Pinciae 1568) MATIENZO, J. Commentaira [sic]... in librum quintum recollectionis legum Hispaniae, (Mantuae Carpentanae 1597)

PAOLO DI CASTRO, Commentaria in secundam codicis partem Comm. in de testamentis, l. cum antiquitas, Ludguni 1561.

VÁZQUEZ DE MENCHACA, De successionum creatione, progresu et resolutione. Tractatus (Salmanticae, 1559). 